\title{
How Does Student Teachers' Emotional intelligence Relate To Their Teaching Competencies?
}

\author{
Mrs.D.Ponmozhi ${ }^{1}$, Prof.Dr.N.O.Nellaiyapen ${ }^{2}$, \\ ${ }^{I}$ Ph.D. Research Scholar, Department of Education, Annamalai University. \\ ${ }^{2}$ Dean and Head, Department of Education. Annamalai University,
}

\begin{abstract}
This research paper is based on the premise that emotional intelligence is required to support the teachers for the purpose of improving their teaching competency. This paper explores the relationship between emotional intelligence and teaching competency of student teachers. The sample consists of student teachers from various colleges of Tamilnadu through random sampling. The Emotional Intelligence Scale -by Upinder dhar, Anukool Hyde \& Sanjyot Pethe and Teaching Competency Scale constructed and standardized by the researchers was used to collect the data. Collected data was tabulated and subjected to statistical analysis. The stepwise regression results revealed that there was significant positive relationship between emotional intelligence and teaching competency of student teachers. Furthermore, it was found that among the ten components of EI, two subscales of emotional stability, self awareness and overall EI were positive predictors of teaching competency of student teachers.
\end{abstract}

Key Words: Emotional intelligence, teaching competency, student teachers.

\section{Introduction}

"Emotional intelligence is the capacity for recognizing our own feelings and those of others, for motivating ourselves, and for managing emotions well in us and in our relationships. Emotional intelligence describes abilities distinct from, but complementary to, academic intelligence or the purely cognitive capacities measured by IQ" (Goleman, 1998). "Emotional intelligence reflects one's ability to deal with daily environment challenges and helps to predict one's success in life, including professional and personal pursuits" (Bar-On, 1997). All these pioneering definitions lead us to conclude that EI is important in shaping one's personality, behavior, style, and competencies.

Competencies are a series of capabilities consisting of knowledge, skills and attitudes. It is a necessary condition for task performance and problem solving. The emotionally intelligent teacher develops certain competencies (knowledge, skill, attitude and values) to perform their task and achieve success in their profession.

\section{Need For The Study}

Emotional Intelligence is a set of qualities and competencies that captures a broad collection of individual skills and dispositions, usually referred to as soft skills or inter and intra-personal skills, that are outside the traditional areas of specific knowledge, general intelligence, and technical or professional skills. Emotions are an intrinsic part of our biological makeup, and every morning they march into the college with student teachers and influence their behaviour. Student teachers show interest in developing certain skills and neglect others. With available skills some teachers succeed well than others. The researcher wants to know the part of emotional intelligence which influences them to develop teaching competencies for their professional life.

\section{Research Objectives}

1. To find whether the emotional intelligence of the student teachers has influence on their teaching competencies.

\section{Hypotheses Of The Study}

1. There is no significant influence of emotional intelligence on teaching competencies.

\section{Materials And Methods}

Normative Survey Method has been used. By using Random Sampling Technique 622 student teachers are selected from Tamilnadu and used as subjects of this study. The Emotional Intelligence Scale standardized by Hyde, A., et al (2001) and Teaching Competency scale standardized by the researchers has been utilized to collect the data from the above mentioned sample of the study. In the present study the word emotional 
intelligence and teaching competency means the scores gained by sample subject on Emotional Intelligence Scale and Teaching competency scale respectively.

The Emotional Intelligence scale comprises of ten sub scales viz; self-awareness, empathy, self motivation, emotional stability, managing relations, integrity, self-development, value orientation, commitment, and altruistic behavior. The questionnaire has 34 questions, on a 5 point Likert scale. The reliability is 0.88 and validity is 0.93 . As per the manual, the tool interpretation has been made i.e. maximum score indicates high emotional intelligence and minimum score indicates low emotional intelligence.

Teaching competency scale comprises of eight sub scales namely adopters, visionaries, collaborators, risk takers, learners, leaders, communicators and model. The questionnaire has 47 questions, on a 5 point Likert scale. The reliability and validity of the scale is 0.85 and 0.92 respectively. Pearson correlation technique and stepwise regression is used to test the hypothesis.

\section{Analysis And Interpretation} calculated

The correlation between emotional intelligence and teaching competencies of student teachers has been

Table.1. Coefficient of Correlation between Emotional intelligence and Teaching Competency.

\begin{tabular}{|c|c|c|c|}
\hline S.No & $\begin{array}{c}\text { Emotional Intelligence } \\
\text { Sub scale }\end{array}$ & $\begin{array}{c}\text { Teaching competency } \\
\text { R Value }\end{array}$ & Result \\
\hline 1 & Self-awareness & $0.52^{* *}$ & $\mathrm{~S}$ \\
\hline 2 & Empathy & $0.52^{* *}$ & $\mathrm{~S}$ \\
\hline 3 & Self motivation & $0.55^{* *}$ & $\mathrm{~S}$ \\
\hline 4 & Emotional stability & $0.43^{* *}$ & $\mathrm{~S}$ \\
\hline 5 & Managing relation & $0.38^{* *}$ & $\mathrm{~S}$ \\
\hline 6 & Integrity & $0.43^{* *}$ & $\mathrm{~S}$ \\
\hline 7 & Self-development & $0.37^{* *}$ & $\mathrm{~S}$ \\
\hline 8 & Value orientation & $0.38^{* *}$ & $\mathrm{~S}$ \\
\hline 9 & Commitment & $0.38^{* *}$ & $\mathrm{~S}$ \\
\hline 10 & Altruistic behavior & $0.39^{* *}$ & $\mathrm{~S}$ \\
\hline 11 & Emotional Intelligence total & $0.65^{* *}$ & $\mathrm{~S}$ \\
\hline
\end{tabular}

The coefficient of correlation between dimensions of emotional intelligence and teaching competency is found to be $0.52,0.52,0.55,0.43,0.38,0.43,0.37,0.38,0.380 .39$ and o.65.It is significant at 0.01 levels. Hence it is concluded that there is significant positive relationship between emotional intelligence sub scales and teaching competencies of student teachers.

Table.2. The Regression shows the relationship between emotional intelligence and teaching competency.

\begin{tabular}{lcccccc} 
Model & b & SE-b & Beta & Pearson r & Sr $^{2}$ & Structure Coefficient \\
\hline (Constant) & 128.624 & 7.932 & & & & \\
Emotional Intelligence total & 1.212 & 0.057 & 0.65 & 0.649 & 0.42 & 0.65 \\
\hline
\end{tabular}

Note. The dependent variable teaching competency. $R^{2}=0.421$, Adjusted $R^{2}=0.420$.

$\mathrm{Sr}^{2}$ is squared semi-partial correlation. $* \mathrm{p}<.001$

Total emotional intelligence was used in a regression analysis to predict teaching competencies. The correlations of variables are shown in table.1.As can be seen correlation between emotional intelligence and teaching competency was significant. The prediction model of emotional intelligence was statistically significant, $\mathrm{F}(1,620)=450.07, \mathrm{p}<.001$, and accounted for approximately $42 \%$ of the variance in teaching competencies $\left(\mathrm{R}^{2}=.0 .421\right.$, Adjusted $\left.\mathrm{R}^{2}=0.420\right)$.

Table.3. The stepwise Regression shows the relationship between emotional intelligence and teaching competency.

\begin{tabular}{lcccccc}
\multicolumn{1}{c}{ Model } & b & SE-b & Beta & Pearson r & Sr $^{2}$ & Structure Coefficient \\
\hline Constant & $\mathbf{1 2 6 . 9 1 1}$ & $\mathbf{7 . 9 2 4}$ & & & & \\
Emotional Intelligence total & 1.225 & $\mathbf{0 . 1 0 7}$ & $\mathbf{0 . 6 5 5}$ & $\mathbf{0 . 6 4 9}$ & $\mathbf{0 . 1 2 0}$ & $\mathbf{0 . 9 9}$ \\
Emotional stability & $\mathbf{- 1 . 1 3 7}$ & $\mathbf{0 . 5 2 3}$ & $\mathbf{- 0 . 0 9 8}$ & $\mathbf{0 . 4 3 1}$ & $\mathbf{0 . 0 0 4}$ & $\mathbf{0 . 6 6}$ \\
Self awareness & 1.091 & $\mathbf{0 . 5 4 9}$ & $\mathbf{0 . 0 8 9}$ & $\mathbf{0 . 5 2 1}$ & $\mathbf{0 . 0 0 4}$ & $\mathbf{0 . 8 0}$ \\
\hline
\end{tabular}

Note. The dependent variable teaching competency. $\mathrm{R}^{2}=0.429$, Adjusted $\mathrm{R}^{2}=0.427$.

$\mathrm{Sr}^{2}$ is squared semi-partial correlation. $\quad * \mathrm{p}<.001$.

Self-awareness, empathy, self motivation, emotional stability, managing relations, integrity, selfdevelopment, value orientation, commitment, and altruistic behavior and total emotional intelligence were used 
in a stepwise multiple regression analysis to predict Teaching Competencies. The correlation of variables are shown in table.1.As can be seen all correlations between emotional intelligence and its subscales with teaching competencies were statistically significant. The prediction model contained three of the eleven predictors and was reached in three steps with no variables removed. The model was statistically significant, $\mathrm{F}(3,618)=154.94, \mathrm{p}<.001$, and accounted for approximately $40 \%$ of the variance of Teaching competencies $\left(\mathrm{R}=0.429\right.$,Adjusted $\left.\mathrm{R}^{2}=0.427\right)$. Teaching competencies is primarily predicted by the lower levels of selfawareness and emotional stability and to a lesser extent by higher levels of total emotional intelligence. The raw and standardized regression coefficient of predictors together with their correlation with teaching competencies, their squared semi-partial correlations, and their structure coefficients are shown in table-3.The total emotional intelligence received the strongest weight in model followed by emotional stability and self-awareness. Selfawareness received the lowest weight of the three weights. With the sizeable correlations between the predictors, the unique variance explained by each of the variables indexed by the squared semi-partial correlation was relatively low: total emotional intelligence, emotional stability and self-awareness, uniquely accounted for approximately $12 \%, 1 \%$ and $1 \%$ of the teaching competencies. Inspection of the structure coefficient suggests that total emotional intelligence and self-awareness was relatively a strong indicator of teaching competencies, and emotional stability was a moderate indicator of emotional intelligence.

\section{Discussion}

The current study was carried out to examine the association between EI and Teaching competency of student teachers. In response to this question, a significant strong positive relationship was reported. This means that those student teachers who feel more competent in their professional competency (Teaching competency) are the ones possessing higher levels of EI. There is a positive correlation between the total EI, factors of EI scores and overall performance (Mishra \& Mohapatra 2010). The yielded result corroborates the findings of the studies conducted by Rastegar and Memarpour (2009), Moafian and Ghanizadeh (2009), Leka\& Kant (2011) and individuals with high EI find themselves in a better position at the workplace irrespective of their position in organizational ladder Gupta \& Chaturvedi(n.d). EI could predict academic performance of college students. (Maraichelvi\& Rajan .2013).

Emotional stability, self-motivation, managing relations, self-awareness and integrity emerged as the best predictors of teacher effectiveness. (Singh \& Jha 2012).Emotional competency is the major contributor towards the overall performance (Mishra \& Mohapatra 2010). The four inner traits that have consistently been found to mark happy people are actually components of EI: Self-esteem, a sense of control, optimism and extraversion. (Myers and Diener, 1995). The model containing the three components of EQ - Flexibility, Optimism and Interpersonal Relationship - could predict 29 percent of the instructors' self-efficacy. (Sarkhosh, ,\& Rezaee,A,A.2014).

\section{Conclusion}

Emotional intelligence and teaching competencies of student teachers were significantly positively correlated. Emotional intelligence helps the student teachers to develop teaching competencies. Even though all dimensions are correlated only sub scales like emotional stability, self-awareness and overall emotional intelligence of student teachers help the student teachers to develop the teaching competencies in recent trends. Thus the teacher education institutions should plan their program to give self awareness in their professional competencies and arrange emotional coaching programs to develop emotional stability among student teachers.

\section{Reference}

[1]. Cooper, R.K. (1997). Applying emotional intelligence in the workplace. Training and Development, 51, 31-33.

[2]. Gardner, L. (2005). Emotional Intelligence and Occupational Stress. (PhD dissertation, Swinburne University, Melbourne, Australia.

[3]. Gibbs, C. (2002). Effective teaching: Exercising self-efficacy and thought control of action. Paper presented at the Annual Conference of the British Educational Research Association,University of Exeter, England.

[4]. Goleman, D. (1998). An EI-Based Theory of Performance, The Emotionally Intelligent Workplace. New York: Bantam Books.

[5]. Gupta,S \& Chaturvedi,S.K.(n.d).Research paper on emotional intelligence and work life balance of employees in the Information technology industry. Retrived from : http://ssrn.com/abstract=2395216.

[6]. Hyde.A., Dhar.U.,\& Pethe. S. (2001). Emotional Intelligence Scale, Lucknow: Vedant publications.

[7]. Kocoglu,Z. (2011). Emotional intelligence and teacher efficacy: a study of Turkish EFL pre-service teachers, Teacher Development: An international journal of teachers' professional development, 15(4), 471-484, DOI:10.1080/13664530.2011.642647.

[8]. Lenka,S.K., \& Kant,R. (2011).Emotional intelligence of secondary school teachers in relation to their professional development. Asian journal of management sciences and education, 1(1). Mahajan,M.(2011).Academic achievement in relation to emotional intelligence and spiritual intelligence,Edutracks, 10 (9),32-36.

[9]. Maraichelvi,A.,\& Rajan,S.(2013). The relationship between emotional intelligence and the academic performance among final year under graduates. Universal Journal of Psychology 1(2): 41-45, retrivedfrom: http://www.hrpub.org DOI: 10.13189/ujp.2013.010203

[10]. Mishra,P.S. \& Mohapatra.A.K.D.(2010).Relevance of Emotional Intelligence for Effective Job Performance: An Empirical Study.Vikalpa ,35(1). 
[11]. Palmer, B. R., Stough, C. Harmer, R., \& Gignac, G. E. (in press). Genos emotionalintelligence inventory. In C. Stough, D. Saklofske, \&, J. Parker (Ed.), Advances in themeasurement of emotional intelligence. New York: Springer.

[12]. Poornima, R. (2011).Emotional intelligence and occupational stress of special education teachers working in the schools of hearingimpaired children, Edutracks, 10 (12), 27-33.

[13]. Rastegar, M., \& Memarpour, S. (2009). "The relationship between emotional intelligence and self-efficacy among Iranian EFL teachers", in System, 37(4): 700-707.

[14]. Sarkhosh,M.,\& Rezaee,A,A.(2014). How does university teachers' emotional intelligence relate to their self-efficacy beliefs? Porta Linguarum, 21.

[15]. Singh,I.,\& Jha,A.(2012). Teacher effectiveness in relation to emotional intelligence among medical and engineering faculty members.Europian journal of psychology,8(4).Retrived from : http://dx.doi.org/10.5964/ejop.v8i4.483

[16]. Subramanyan,K.(2011).Impact of emotional intelligence and study skills of high school students.Edutracks, 10 (6),36-38.

[17]. Sutton, R. E., \& Wheatley, K. F. (2003). Teachers' emotions and teaching: A review of theliterature and directions for future research, Educational Psychology Review, 15(4):327-358. 